\title{
Synthesis and Characterization of Surface Modified Cellulose Nanofibers from Banana Peel
}

\author{
Velayudham Navaneetha Krishnan and Atmakuru Ramesh* \\ Department of Analytical Chemistry, International Institute of Bio-technology and Toxicology (IIBAT), \\ Padappai, Chennai 601 301, Tamil Nadu, India.
}

\begin{abstract}
Cellulose nanofibers were separated from banana peel by pretreatment, chemical treatment, mechanical treatment and disintegration methods like sonication, cryo crushing and dissolution. Further, cellulose nanofibers were treated with acetic acid and acetic anhydride in presence of pyridine. The obtained cellulose fibers was characterized by Fourier Transformation Infrared Spectroscopy (FT-IR) and confirm the presence of $\mathrm{OH}, \mathrm{C}-\mathrm{H}$ bond and $\mathrm{C}-\mathrm{O}-\mathrm{C}$ groups in the synthesized Banana Peel Cellulose Nanofibers (BCNF) and presence of $\mathrm{OH}, \mathrm{C}-\mathrm{H}, \mathrm{C}-\mathrm{O}-\mathrm{C}$ and $\mathrm{CH}_{3} \mathrm{CO}$ in the Acetylated Banana Peel Cellulose Nanofibers (Acetylated BCNF). The Size of BCNF and Acetylated BCNF were investigated by Field Emission Scanning Electron Microscope (FESEM) and Transmission Electron Microscopy (TEM). The synthesized BCNF and Acetylated BCNF investigated by FESEM and TEM was around $90 \mathrm{~nm}$ to $150 \mathrm{~nm}$ and $30 \mathrm{~nm}$ to $60 \mathrm{~nm}$ respectively. X-Ray Diffraction (XRD) Analysis was carried out for the BCNF and Acetylated BCNF. XRD result shows that synthesized $B C N F$ and Acetylated $B C N F$ were partially amorphous. The structural morphology was confirmed with the Atomic Force Microscopy (AFM). The Acetylated BCNF were successfully utilized in the preparation of membrane for water purification.
\end{abstract}

Keywords: Banana Peel, BCNF, Acetylated BCNF, FT-IR, FESEM,TEM, XRD and AFM.

\section{Introduction}

Cellulose is a major constituent in the cell walls of the plant material. In the recent years extensive efforts have been taken for the development of cellulose based composite materials for different industrial purpose due to its biodegradability, renewability, low cost and non-petroleum based source ${ }^{1}$. Cellulose are polysaccharides and most abundant natural polymers. Cellulose is a linear homopolymer of $\beta-D-1,4$ glucose units linked by glucosidic bond. It is comprised of microfibrils having nano size diameter and surrounded by lignin and hemicelluloses ${ }^{2}$. Cellulose based biopolymers prepared from the cellulose rich materials were used in preparation of several biocomposite materials ${ }^{3-6}$. Cellulose has a strong affinity and hydrogen bonding through the Vander Val's force to itself, hence it is very stable and insoluble in water and most of the solvents. Cellulose Nanofibers are used in various application due to their low density, large surface area and aspect ratio, noticeable flexibility, specific barrier properties and low thermal expansion ${ }^{7}$.

Peel of banana is an excellent source of cellulose fiber which can be used as a biomaterial, as peel represents $40 \%$ of total fruit weight of banana. Unfortunately, peels are being often discarded and proceeding a serious pollution problem. The utilization of this cellulose rich biomass would not only increase value of this agrowaste but also help to overcome environmental pollution issues. The bran was prepared from the peel of unripe green bananas of the variety of Robusta. The fruit was harvested at Chennai, Tamil Nadu. It is more appropriate to use the unripe banana peel instead of the ripe fruit because the enzymatic synthesis of the fruit occurs during maturation, which partially degrades cellulose to monosaccharides.The physical and chemical properties of cellulose and its chemical reactivity and behavior are strongly influenced due to the arrangement of the hydroxyl group and hydrogen bonding with relation to each other and to the fiber axis. Native cellulose is arranged by sequences like amorphous region and crystalline region. When it undergoes chemical reaction, the amorphous region could get wrecked and the crystalline region isolated. Carboxylate cellulose nanocrystals are prepared from cotton linters by Tempo oxidation method $^{8}$ Cellulose nanofibers are synthesized from wheat straw by chemical and mechanical treatment ${ }^{9,} 10$. The cellulose fibers have established great industrial applications, however the insufficient manufacturing technology hinder their commercial applications ${ }^{11}$. Cellulose, in its nano form, has great potential in emerging medical and environmental applications and it has proven to be a good heat transfer material ${ }^{12-14}$. Cellulose fiber has contributed in its use in paper and other fiber based composite materials in adsorbents, textile industry, cosmetics and medical fields. The electro-spinning process makes it possible to produce 50 to $500 \mathrm{~nm}^{15}$. The $\mathrm{HNO}_{3}-$ $\mathrm{KClO}_{3}$ treatment is performed to produce biocomposites used from the bamboo plant ${ }^{16}$. The aim of this study is to prepare acetylated cellulose nanofibers from banana peel through chemical and mechanical treatment. 


\section{a. Materials - Reagents and Chemicals}

\section{Materials And Methods}

The banana's were received from karuna gardens near Chennai, Tamil Nadu. Chemicals such as potassium metabisulfite, sodium hydroxide, sodium chlorite, acetic acid, sulfuric acid, acetic anhydride, pyridine, anthraquinone, liquid nitrogen and potassium bromide were supplied from Merck Specialties Pvt., Ltd., India. These chemicals were pure and analytical grade chemicals, used directly without any purification.

\section{b. Materials: Instrumentation}

\subsubsection{Fourier Transformer Infrared Spectroscopy (FT-IR)}

The FT-IR studies were carried out with FTIR spectrometer (Model - 8400S, Shimadzu) for BCNF and Acetylated BCNF to identity the presence of functional group. The $\mathrm{KBr}$ pellet technique was followed for FT-IR characterization. Around $2.5 \mathrm{mg}$ of samples and $250 \mathrm{mg}$ of $\mathrm{KBr}$, transferred into a pestle and mortar and ground well. The pellets were prepared under vacuum using a specified device. The scanning range was frmom 400 to $4000 \mathrm{~cm}^{-1}$.

\subsubsection{Field Emission scanning Electron Microscopy (FESEM)}

The size of BCNF and acetylated BCNF were characterized by Fourier Emission Scanning electron microscopy (FESEM) analysis at high resolution, Model- Quanta FEG 200, FEI. The specimen was placed on the grids, at $3 \mathrm{kv}$ acceleration voltage with SE mode and observed.

\subsubsection{Transmission Electron Microscopy (TEM)}

The morphology and size of acetylated BCNF were investigated by Transmission Electron Microscopy (TEM), model Hitachi S-3400N, Japan. The specimen images of the nanofibers were recorded.

\subsubsection{X-ray Diffraction Analysis (XRD)}

X-ray diffraction analysis helps to know the crystallinity and amorphous nature of BCNF and acetylated BCNF. Microcrystalline cellulose was used as reference for XRD characterization, sourced from Merck Specialties, Mumbai. The X-ray diffraction is a Panalytical XPert Pro XRD with both, powder mode and GI Attachments. The patterns are detected on XPert High Score Plus software.

\subsubsection{Atomic Scope Microscopy (AFM)}

AFM was carried out to investigate structural parameters (dimensions) of the BCNF and acetylated BCNF. Tapping mode was used on a Nanoscope SPM microscope (Veeco Instruments) with a Bruker RTESP tip. Samples were prepared by drying a droplet of a very dilute dispersion of nanofibers on a silicon wafer.

\section{Methods}

\subsubsection{Pretreatment:}

The banana peels were manually removed and immediately immersed in a $1 \%$ potassium metabisulfite solution for $24 \mathrm{~h}$, to inhibit oxidation. Next, they were arranged in aluminium trays and dried in an oven at 60C for $24 \mathrm{~h}$. The dried peels were then milled in an IKA blender. The pulp was washed with ethanol, to remove lipid fractions and dried again in an oven at $60^{\circ} \mathrm{C}$ for $24 \mathrm{~h}$. The resulting materials were sieved through a 200 mesh sieve, which afforded microparticles.The CFs were isolated using chemical (alkali-acid hydrolysis) treatment as described by with some modifications. The peel flour was cooked in a digester (KelPlus, Pelican Equipment, Chennai, India) with solution of $20 \%(\mathrm{w} / \mathrm{v})$ sodium hydroxide $(\mathrm{NaOH})$ and $0.1 \%$ anthraquinone in 1:20 ratio of peel flour to alkali solution at $170^{\circ} \mathrm{C}$ for $1.5 \mathrm{~h}$. The alkali treatment helped in partial removal of lignin, hemicelluloses and pectin followed by washing and neutralized with deionized water.

\subsubsection{Chemical Treatment:}

The remaining insoluble material was given bleaching treatment at $70^{\circ} \mathrm{C}$ for $1 \mathrm{~h}$ with $1 \%(\mathrm{w} / \mathrm{v}$ ) sodium chlorite $\left(\mathrm{NaClO}_{2}\right)$ at $\mathrm{pH} 5$ (adjusted with $10 \%$ acetic acid) and was repeated three times. This step helped in leaching out of non-cellulosic compounds and confirmed by effective discoloration of peel flour in each chemical step. Any remaining insoluble pellets persisted after three steps bleaching process was further treated with $10 \%$ potassium hydroxide $(\mathrm{KOH})$ solution at $80^{\circ} \mathrm{C}$ for $2 \mathrm{~h}$ to remove residual hemicelluloses. The materials were washed, neutralized and finally acid hydrolyzed with $1 \%$ sulphuric acid at $80^{\circ} \mathrm{C}$ for $1 \mathrm{~h}$.

\subsubsection{Acid Hydrolysis:}

The acid hydrolysis treatment aided in leaching out traces of minerals, residual starch and also hydrolyzed amorphous cellulose and eased in getting the required nanofibers. After each chemical treatment, the insoluble pellets were neutralized by washing with deionized water and kept in water-swollen state to avoid 
hydrogen bonding generation among nanofibers .The chemical treatment resulted in pure white banana peel cellulose fibers (BCF) in gel like appearance and was further disintegrated to reduce the size of BCF in nanorange. The chemically purified $\mathrm{BCF}(0.5 \%)$ was suspended in $120 \mathrm{~mL}$ deionised water and was given highintensity ultrasonic treatment (UW 2070, Bandelinsonoplus, China)

\subsubsection{Dissolution:}

The BCNF were mixed with $0.1 \mathrm{~N}$ sodium hydroxide solution, sonicated for $2 \mathrm{~h}$. Then the pulp was washed with distilled water by centrifugation and the $\mathrm{pH}$ maintained as neutral. Dried pulp was taken into a 100 $\mathrm{mL}$ stopper conical flask and $50 \mathrm{~mL}$ of distilled water was added and stirred with a magnetic pellet for $48 \mathrm{~h}$ and dried at $50^{\circ} \mathrm{C}$ up to dryness. The dried pulp was ground well by gradual addition of liquid nitrogen thrice. The resulting fiber was characterized by FT-IR, FESEM, XRD and AFM.

\subsubsection{Surface modification of Cellulose - Acetylation:}

Acetylation of banana peel cellulose nanofibers (BCNF) was achieved by heterogeneous procedure without solvents using acetic acid and acetic anhydrid in the presence of pyridine as a catalyst. The BCNF were dried at $100^{\circ} \mathrm{C}$ in an oven, cooled in desiccators. A $2.0 \mathrm{~g}$ of BCNF were placed in a $250-\mathrm{mL}$ round bottom flask, adequate amount of acetic anhydride, acetic acid and pyridine were added to the flask, to ensure that the fibers were totally covered with the reagent. In order to avoid thermal degradation of the fibers, the flask was heated at $100^{\circ} \mathrm{C}$ under reflux at atmospheric pressure. The reaction was performed for 4 hours, and at the end of the reaction the treated fibers were separated from suspension by filtration and washed with distilled water for several time in order to remove unreacted acetic anhydride and acetic acid by-products. The acetylated cellulose nanofibers were dried at $100^{\circ} \mathrm{C}$ overnight, then placed in desiccators and held at room temperature. The resulting fiber was characterized by FT-IR, FESEM, TEM, XRD and AFM.

\subsection{FTIR Spectrum of BCNF and Acetylated BCNF:}

\section{Results And Discussion}

Figure-1 shows the FTIR spectra of BCNF having sharp bands but similar to that observed in acetylated $\mathrm{BCNF}$ in the region $1649-1634 \mathrm{~cm}^{-1}$ are due to the $\mathrm{O}-\mathrm{H}$ bending due to adsorbed water ${ }^{17}, 1430$ $1420 \mathrm{~cm}^{-1}$ is due to $\mathrm{CH}_{2}$ scissoring motion in cellulose), 1382-1375 $\mathrm{cm}^{-1}$ (C-H bending), 1336 (O-H in plane bending) $1317 \mathrm{~cm}^{-1}\left(\mathrm{CH}_{2}\right.$ wagging), $1054 \mathrm{~cm}^{-1}$ (C-O-C pyranose ring stretching vibration), 902-893 $\mathrm{cm}^{-1}$ (associated with the cellulosic $\beta$ - glycosidic linkages), $\sim 1155 \mathrm{~cm}^{-1}$ (C-C ring stretching band ), and at $1105 \mathrm{~cm}$

${ }^{1}$ (the $\mathrm{C}-\mathrm{O}-\mathrm{C}$ glycosidic ether band) ${ }^{18}$. The spectral bands observed at $1427 \mathrm{~cm}^{-1}$ and $897 \mathrm{~cm}-1$ shows significant cellulose I content. In case of BCNF, spectral band at $1375 \mathrm{~cm}^{-1}$ was very strong while spectral band at $1335,1315 \mathrm{~cm}^{-1}$ overlap and diffused and other spectral band $1278-1285 \mathrm{~cm}^{-1}$ is weak and diffused. On comparing these spectral data which revealed that BCNF are composed of crystalline cellulose I while content of amorphous cellulose is negligible. These FTIR spectral peaks can be applied to analysis of crystallinity of the samples consisting cellulose I or Cellulose II or mixture of both components, and amorphous cellulose. A $850-1500 \mathrm{~cm}^{-1}$ region is sensitive to crystal structure of the cellulosic material ${ }^{20}$. Spectral bands at $1420-1430 \mathrm{~cm}^{-1}$ and $893-897 \mathrm{~cm}^{-1}$ are very important to elucidate to the crystal structure of cellulosic material and its $\left(1420 / 893 \mathrm{~cm}^{-1}\right)$ spectral ratio and $\left(1375 / 2900 \mathrm{~cm}^{-1}\right)$ spectral ratio show index of crystallinity or lateral order index (LOI) and total crystallinity index (TCI), respectively. In cellulosic samples, the spectral ratio $\left(1430 / 897 \mathrm{~cm}^{-1}\right)$ gives the evidence of containing cellulose $\mathrm{I}^{21}$. Higher value of the given index (LOI, TCI) reveals that the given material contains a highly crystalline and an ordered structure 24 . For these index values, the $\left(1430 / 897 \mathrm{~cm}^{-1}\right)$ spectral ratio is low in case of acetylated BCNF as compared to BP due to chemical treatments which possibly disturbed the order of the structure to some extent and in case of BCNF increased to higher value due to removal of amorphous cellulose while the $\left(1375 / 2900 \mathrm{~cm}^{-1}\right)$ spectral ratio increased from BP to acetylated BCNF to BCNF (very high values in case of BCNF).

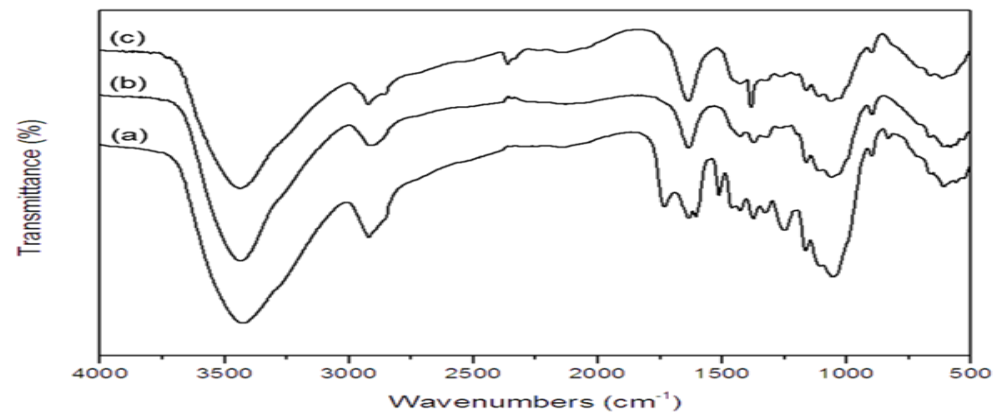

Figure-1. FTIR spectra of (a) Banana Peel as Raw Material (BF); (b) Banana Peel Cellulose Nanofibers (BCNF); and (c) Aceylated Banana Peel Cellulose Nanofiber (Acetylated BCNF). 


\subsection{Characterization on BCNF and Acetylated BCNF:}

Figure-2 and Figure-3 shows the XRD patterns of BCNF and Acetylated BCNF respectively. From the XRD characteristics of BCNF and Acetylated BCNF, a broad peak at $2 \theta=23^{\circ}$ and reveals the amorphous nature of banana peel ${ }^{22}$. The peaks are broad on the nanomaterials, which indicate the presence of more of amorphous content in the nanomaterials. It could be more important due to having crystalline and amorphous regions; which will generate a more reactivity with the other chemicals to achieve the nano material functionality. The process of acetylating reduced the crystallinity of the fibers ${ }^{23}$. It was observed clearly that material obtained from banana peel fiber has a partial amorphous and crystalline nature.
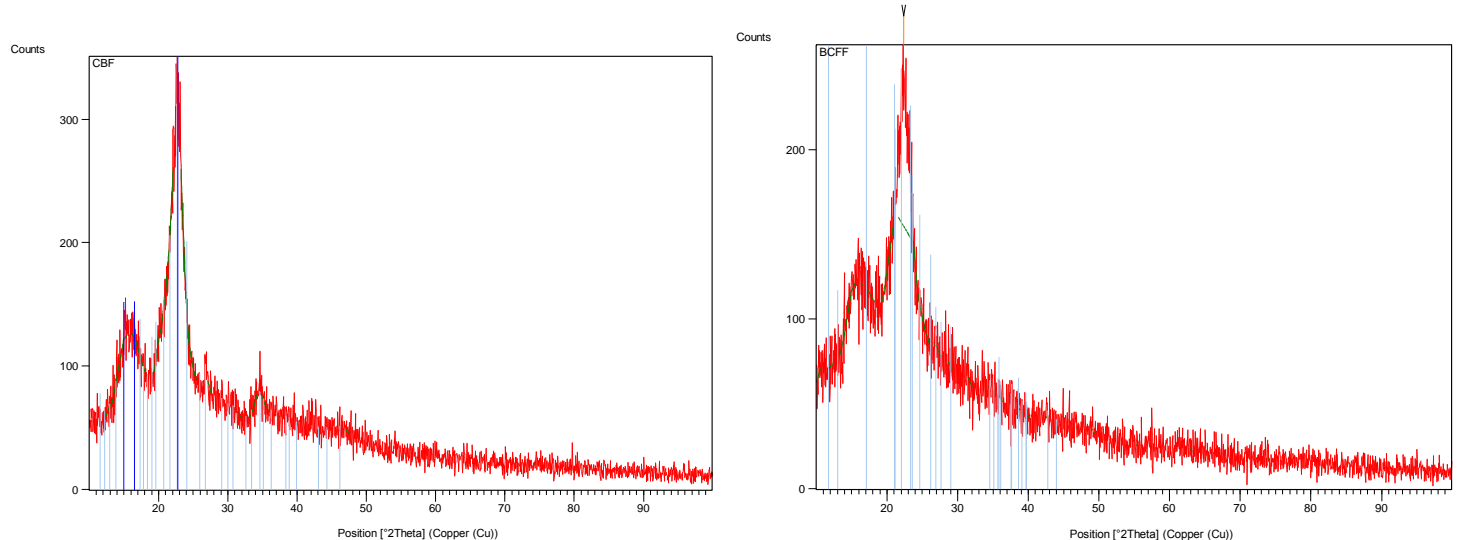

Figure-2. XRD Patterns of BCNF

Figure-3. XRD Patterns of Acetylated BCNF

\subsection{FESEM and TEM Analysis of $\mathrm{BCNF}$ and acetylated BCNF:}

Figure 4. shows the morphological structure and size of BCNF and Acetylated BCNF. FESEM and TEM image of BCNF obtained by banana peel fiber is represented in the range of $80-130 \mathrm{~nm}$ while acetylated $\mathrm{BCNF}$ range is $20-50 \mathrm{~nm}$ it is smaller to compare with BCNF.

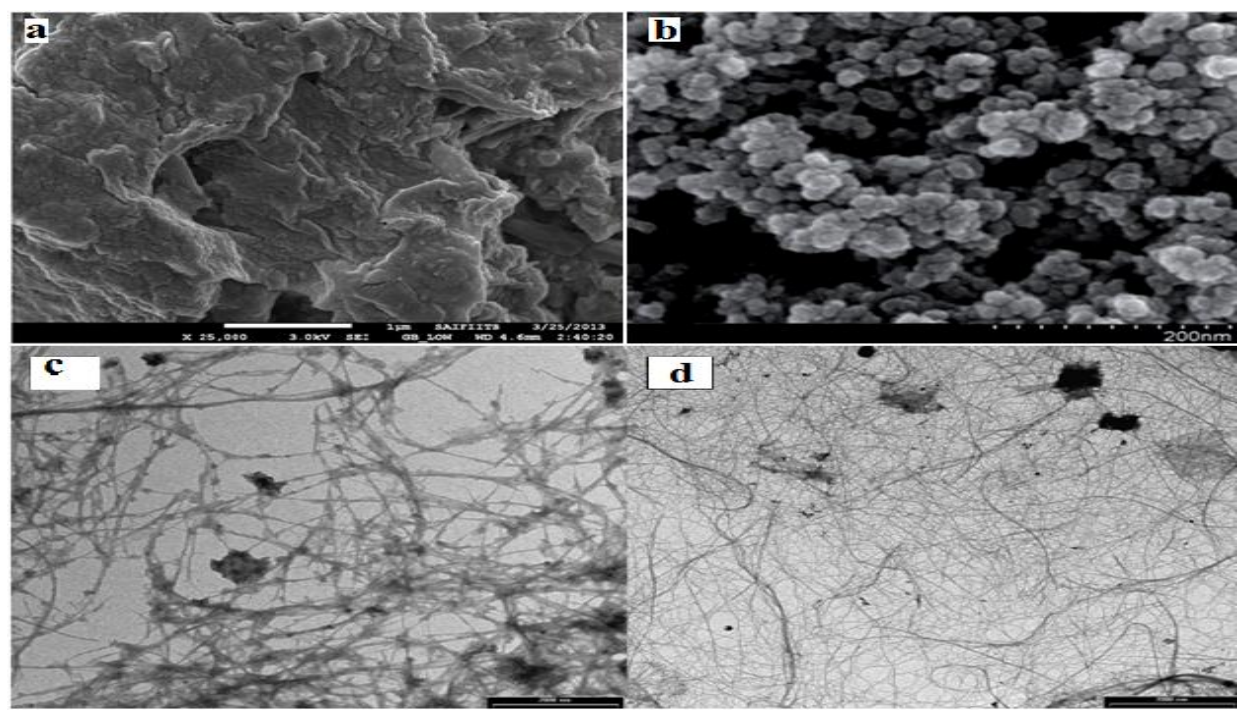

Figure-4. (a) and (b) FESEM images of morphology of BCNF Acetylated BCNF, (c) and (d) TEM Images of Acetylated Cellulose Nanofibers Obtained at Various Scale

\subsection{AFM Analysis}

Figure-5 represents the AFM image of BCNF and acetylated BCNF. The nanofiber suspension obtained after the high pressure defibrillation was analyzed to determine diameters using AFM. The AFM image of Figure-5 (a) shows the structural morphology of BCNF. It is seen that the fibers are indeed nano sized and the diameter of nanofibers is within the range $90 \mathrm{~nm}-150 \mathrm{~nm}$. Figure-5 (b) shows the structural morphology of Acetylated BCNF. It is seen that the fibers are in the range of $30-60 \mathrm{~nm}$. 

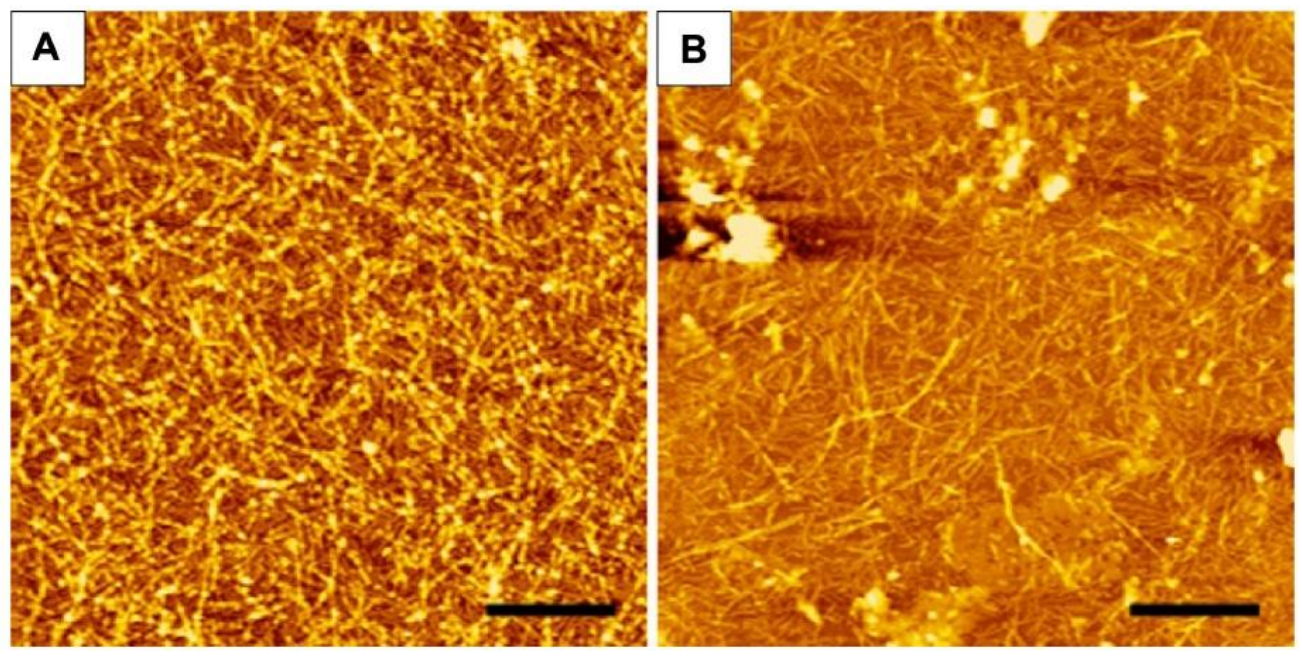

Figure-5. AFM Image of the BCNF and Acetylated BCNF

\section{Conclusions}

This study is to demonstrate that the cellulose nanofibers can be synthesized from the banana peel through simple methods like pretreatment, chemical treatment, mechanical treatment followed by dissolution. The cellulose nanofibers were acetylated and characterized by FT-IR, XRD, FESEM, TEM and AFM analysis. The results show that the synthesized acetylated cellulose nanofibers were within the range between $30 \mathrm{~nm}-60$ $\mathrm{nm}$. The hydroxyl group in the cellulose nanofibers was replaced by the acetyl group in the acetylation process; it might be change the properties of cellulose nanofibers, due to its structural modification. The results indicate that the acetylated cellulose nanofibers from banana peel can be useful in preparation of membrane, biocomposite, biomedical application and packaging materials.

\section{Acknowledgements}

The authors are thankful to the management of IIBAT for valuable support and encouragement.

\section{References}

[1]. R.J. Moon, A. Martini, J. Nairn, J. Simonsen, J. Youngblood, Cellulose nanomaterials review: structure: properties and nanocomposites, Chemical Society Reviews, 40, 3941 (2011).

[2]. Y. Habibi, L.A. Lucia, O.J. Rojas, Cellulose nanocrystals: chemistry, self-assembly, and applications, Chemical Reviews 3479 , (2010).

[3]. W.A. MacDonald, J.Mater.Chem.14, 4 (2004)

[4]. S.R. Forrest, Nature, 428, 911 (2004).

[5]. R .H. Reuss, , B. R. Chalamala, A. Moussessian, , M. G. Kane, A. Kumar, D. C. Zhang, J. A. Rogers, M. Hatalis, D. Temple, G.Moddel, B. J. Eliasson, M. J. Estes, J. Kunze ,E. S. Handy, E. S. Harmon, D. B. Sa lzman J. M.Woodall, M. A. Alam, J. Y. Murthy, S. C. Jacobsen, M. Olivier, D. Markus P. M. Campbell and E. Snow, Proc.IEEE. 93, 1239 (2005).

[6]. M. Nogi and H. Yano, Adv.Mater. 20, 1849 (2008).

[7]. D. Liu, X. Chen, Y. Yue, M. Chen, Q. Wu, Carbohydrate Polymers, 84, 316, (2011).

[8]. S. Montanari, M. Roumani, L. Heux and Michel R. Vignon. Macromolecules. 38,1665-1671 (2004)

[9]. Thygesen and A. Oddershede, Cellulose. 12, 563 -576 (2005)

[10]. Sain and M. Panthapulakkal, Ind. Crops Prod. 23, $1-8$ (2006)

[11]. Micheal T. Postek, A. Vladar, J. Dagata, N. Farkas, B. Ming and Theodore H. Wegner, 24, 296 -308 (2006)

[12]. T. Nishino, I. Matsuda, K. Hirao, Macromolecules. 37, (2004)

[13]. M. Nogi, K. Handa, A. N. Nakagaito, H. Yano, Appl.Phys.Lett. 87, 243-110 (2005)

[14]. Y. Shimazaki, Y. Miyazaki, Y. Takezawa, M. Nogi, K. Abe, S. Ifuku and H. Yano, Biomacromolecules. 8, 2976 (2007)

[15]. D. J. Gardner, G. S. Oporto, R. Mills and M. A. S. Azzi Samir, Journal of adhesio n science and technology. 22, 545-567 (2008)

[16]. P. stand and M. Andresen, Cellulose. 15, 35 - 45 (2008)

[17]. Troedec, M., Sedan, D., Peyratout, C., Bonnet, J., Smith, A., Guinebretiere, R., Gloaguen, V., and Krausz, P., Composites Part AAppl. Sci. Manufact., 39, 514-522, (2008)

[18]. Mandal, A., and Chakrabarty, D., Carbohydr. Polym, 86, 1291-1299, (2011)

[19]. Garside, P., and Wyeth, P., , Stud. Conser, 48, 269-275, (2003)

[20]. Carrillo, F., Colom, X., Sunol, J. J., and Saurina, J., Eur. Polym. J., 40, 2229 (2004)

[21]. Oh, S. Y., Dong, I. Y., Shin, Y., Hwan, C. K., Hak, Y. K., Yong, S.C., Won, H. P., and Ji. H. Y., Carbohydr. Res., 340, 2376-2391, (2005)

[22]. Rosa, M. F., Medeiros, E. S., Malmonge, J. A., Gregorski, K. S., Wood, D. F., Mattoso, L. H. C., et al. (2010).

[23]. Mehdi Jonoobi, Jalauddin Haru, cellulose, 17, 299 (2010)

[24]. Spiridon, I., Teaca, C.A., and Bodirlau, R., Bioresources, 6, 400-413, (2010) 